\title{
The Localization and Secretion of a Proteolytic Enzyme Complex by the Dermatophytic Fungus Microsporum canis
}

\author{
By J. O'S ULLIVAN AND G. E. MATHISON \\ Department of Microbiology, Queen Elizabeth College, \\ Campden Hill Road, London, W. 8 \\ (Accepted for publication 30 July 1971) \\ SUMMARY
}

\begin{abstract}
The dermatophyte, Microsporum canis, synthesized a complex of proteolytic enzymes localized in discrete organelles in the mycelium. On induction by protein in the growth medium, the intracellular level rose sevenfold and the enzymes appeared in the culture medium. The process is thought to be true secretion since an autolytic marker enzyme was present in insignificant amounts during the exponential growth phase when the proteases appeared. Amino acids in the medium repressed the synthesis of extracellular proteases.

The protease complex had $\mathrm{pH}$ optima at $6 \cdot 6,8 \cdot 0$ and $9 \cdot 5$ to $10 \cdot 0$ and showed endopeptidase rather than exopeptidase activity. The possible relevance of such an enzyme system to the pathogenicity and keratinophilia of Microsporum canis is discussed.
\end{abstract}

\section{INTRODUCTION}

The mechanism by which dermatophytes cause the characteristic features and symptoms of dermatophytosis is only partially understood. In view of the ecological association of dermatophytes with keratinized tissues both as saprophytes and as parasites there is reason to suppose that a study of the proteolytic systems of these fungi will shed light on the mechanism of pathogenesis. That dermatophytes are actively keratinolytic in their saprophytic stage is well established (Mercer \& Verma, I963; English, 1963, I968; Mathison, I 964; Weary, Canby \& Crawley, I965; Baxter \& Mann, I969). Keratinolysis, as distinct from the proteolysis of less recalcitrant epidermal proteins, is probably less important in vivo once the mycelium is established in the epidermis. It has been shown for example that, in hairs naturally infected by Microsporum gypseum, it is mainly the non-keratinized protein which is decomposed (Keddie, 1967).

The proteolytic activities of a number of dermatophytes have been investigated (Cruikshank \& Trotter, 1956; Chattaway, Ellis \& Barlow, 1963; Chesters \& Mathison, 1963) and, more recently, enzymes involved have been partially purified and characterized (Roberts \& Doetsch, 1967; Day et al. I968; Yu, Harmon \& Blank, I969). The object of this communication is to present some of the features of the proteolytic system of Microsporum canis, viz. the control of the secretion of proteolytic enzymes and their localization within the cell, which may be pertinent to an understanding of the ecological role of the system.

\section{METHODS}

Cultivation of organism. The fungus was grown in $250 \mathrm{ml}$. conical flasks containing $25 \mathrm{ml}$. of medium. Flasks were inoculated with spores to give an initial concentration of $1 \times 10^{6}$ viable units $/ \mathrm{ml}$. and shaken on an orbital incubator (Gallenkamp \& Co. Ltd, London, EC 2) 
at $200 \mathrm{rev} . / \mathrm{min}$. and $30^{\circ}$. The medium contained (g./1.) $\mathrm{CaCl}_{2} \cdot 2 \mathrm{H}_{2} \mathrm{O}, 0.005 ; \mathrm{MgSO}_{4} \cdot 7 \mathrm{H}_{2} \mathrm{O}$, $\mathrm{I} \cdot 0 ; \mathrm{ZnSO}_{4} \cdot 7 \mathrm{H}_{2} \mathrm{O}, 0.007$; and either casein or casein hydrolysate, 20 : the latter acted as both

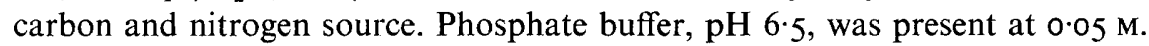

Assay for proteolytic activity. The method used was that of Anson (1938) as modified by Kunitz (I947). The reaction mixture consisted of casein solution (I \%, w/v; I.O ml.) O.I Mphosphoric acid/boric acid buffer ( $1 \cdot 0 \mathrm{ml}$.) and enzyme solution ( $\mathrm{I} \cdot \mathrm{O} \mathrm{ml}$.). The buffer consisted of a solution containing $0.2 \mathrm{M}$-boric acid and $0.2 \mathrm{M}$-phosphoric acid to which was added the appropriate amount of $\mathrm{I} \cdot \mathrm{O} \mathrm{M}-\mathrm{NaOH}$. The final volume was adjusted with water to bring the molarity of the phosphoric acid/boric acid mixture to $\mathrm{O}^{\mathrm{I}} \mathrm{M}$. A pH range between 6.0 and II.0 was possible using this system.

Trichloracetic acid $(20 \%, \mathrm{v} / \mathrm{v} ; \mathrm{r} \cdot 0 \mathrm{ml}$.) was used to stop the reaction and $\mathrm{r} \cdot 0 \mathrm{ml}$. of the resulting supernatant was assayed for TCA-soluble Folin-Ciocalteu reactive material, this activity being expressed as tyrosine by comparison with tyrosine standards. One enzyme unit was that amount of enzyme which liberated hydrolytic products equivalent to I $\mathrm{m} \mu$ mole of tyrosine per min. at $30^{\circ}$.

Assay for peptidase activity. Using a range of commercially available synthetic peptides four methods were employed: (i) by the measurement of liberated carboxyl groups using a pH-stat (Schwert, Neurath, Kaufman \& Snoke, I948); (ii) by the method of Smith (I955) with $\mathrm{Mn}^{2+}$ as activator and titration of the free carboxyl by the method of Grassman \& Heyde (I929); (iii) by the estimation of free amino acids with the modified Yemm and Cocking ninhydrin reagent according to Matheson \& Tattrie (I964); (iv) by thin-layer chromatography using silica gel G coated plates (E. Merck Ag., Darmstatt, W. Germany). The solvent was butan-I-ol + glacial acetic acid + water $(8+2+2$, by vol. $)$.

Assay for alkaline phosphatase activity. Phosphatase was measured by recording the change in absorption at $4 \mathrm{IO} \mathrm{nm}$. in a reaction mixture consisting of $0.05 \mathrm{M}-p$-nitrophenyl phosphate $(\mathrm{I} \cdot 0 \mathrm{ml}$.$) , 0 . \mathrm{I} \mathrm{M}$ tris- $\mathrm{HCl}$ buffer $\mathrm{pH} 8.4(5.0 \mathrm{ml}$.) and suitably diluted enzyme ( $1 \cdot 0 \mathrm{ml}$.) after stopping the reaction with $\mathrm{I} \cdot 0 \mathrm{ml}$. of $\mathrm{I} \cdot \mathrm{O}$ M-sodium carbonate. One unit of activity was that amount of enzyme which catalysed the release of I $\mu$ mole of $p$-nitrophenol per min. at $30^{\circ}$.

Estimation of protein. The method of Lowry, Rosebrough, Farr \& Randall (I95I) was used.

Sucrose density-gradient centrifugation. Discontinuous sucrose gradients (50 to $20 \%, \mathrm{w} / \mathrm{w}$ ) were prepared manually and allowed to stand overnight at $4^{\circ}$ after which they were approximately linear as assessed by refractive index measurements. Intracellular enzyme was prepared by sand grinding the mycelium in $0.25 \mathrm{M}$-sucrose, centrifuging at $500 \mathrm{~g}$ for $10 \mathrm{~min}$. to remove coarse debris and recentrifuging at $35,000 \mathrm{~g}$ for $30 \mathrm{~min}$. The resulting pellet was suspended in $0.25 \mathrm{M}$-sucrose and $2 \mathrm{ml}$. of this placed on top of the gradient (total volume $18 \mathrm{ml}$.). The gradients were placed in a $3 \times 20 \mathrm{ml}$. swing out centrifuge head and spun for $90 \mathrm{~min}$. at $30,000 \mathrm{rev} / \mathrm{min}$. (35,000 to I I $5,000 \mathrm{~g}$ ) in an MSE Automatic Superspeed 50 T.C. centrifuge. The gradients were sampled from the bottom in I ml. fractions.

Where Triton X-Ioo was required in the reaction mixtures it was included at a final concentration of $0 . I \%(\mathrm{v} / \mathrm{v})$. Samples from the sucrose density gradients were assayed without further treatment other than dilution. The inherent errors and precautions necessary when using Folin-Ciocalteu reagent in the presence of sucrose are discussed elsewhere (O’Sullivan \& Mathison, 1970). 


\section{RESULTS}

Characteristics of growth and extracellular production of enzymes. The progress of mycelial growth and enzyme production on media containing either casein or casein hydrolysate is shown in Fig. I. Microsporum canis grew exponentially in submerged culture with a specific growth rate of $0.05 \mathrm{~h}^{-1}$ on casein (doubling time, $14 \mathrm{~h}$.) and $0.06 \mathrm{~h}^{-1}$ on casein hydrolysate

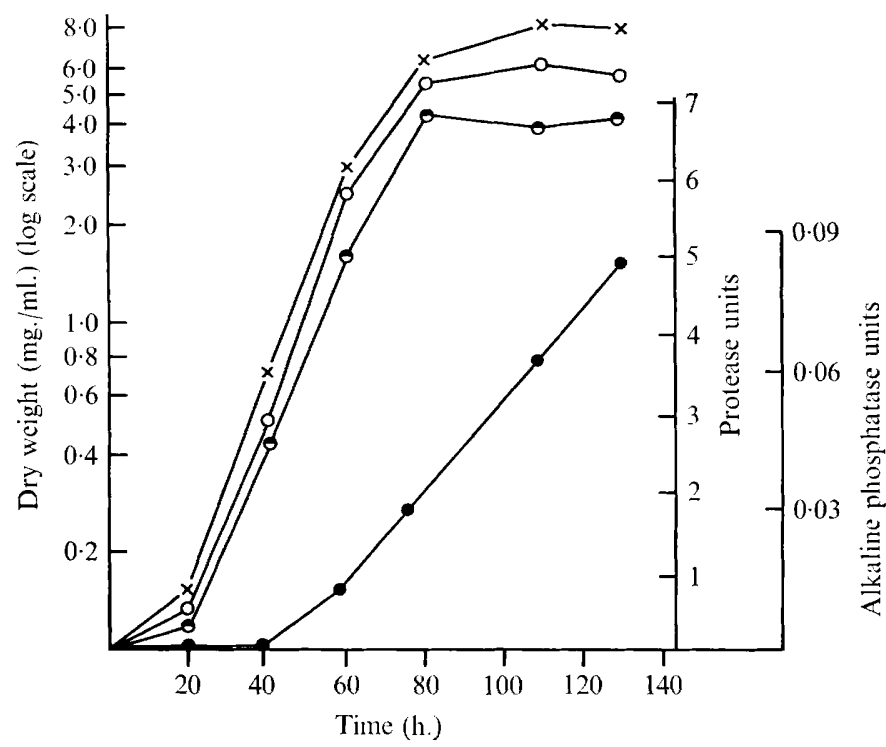

Fig. I. The growth of Microsporum canis and secretion of proteases. Proteases $(\Theta-\Theta)$ were secreted when the fungus was grown on a casein-containing medium $(x-x)$ but not when grown on casein hydrolysate $(\mathrm{O}-\mathrm{O})$. Alkaline phosphatase $(-)$ was found in the culture filtrate at low levels during growth on both substrates.

(doubling time, I I h.). Final yields of $8 \mathrm{mg} . / \mathrm{ml}$. dry weight were reached on casein with rather lower yields on casein hydrolysate. Proteolytic enzymes were found in the culture filtrate when the organism was growing on casein but not when casein hydrolysate was present in the medium. The enzymes appeared first at the beginning of the exponential phase of growth and steadily increased until most of the substrate was exhausted, when the level declined. It rose again when the autolytic phase commenced.

Some autolysis is known to take place during the phase of active growth. It was thus important to establish whether the protease in the culture filtrate was a product of cell lysis or of secretion. Evidence that a secretory mechanism was involved was obtained by following the appearance of alkaline phosphatase in the culture filtrate. This enzyme can be used as an indicator of cell lysis in Microsporum canis. Its appearance in the culture filtrate lagged some $30 \mathrm{~h}$. behind the appearances of protease and when it appeared the levels were much less than those measured in cultures which had been allowed to proceed to the autolytic phase (O'Sullivan, I970). A similar degree of autolysis occurred during growth of $M$. canis on casein hydrolysate without extracellular proteinase formation, lending support to the view that the protease was secreted.

The $\mathrm{pH}$ profile of the activity of the crude extracellular preparation showed three peaks: at $\mathrm{pH} 6.6$, at $\mathrm{pH} 8.0$ and a broad peak between $\mathrm{pH} 9.5$ and $\mathrm{I0} \cdot 0$. This pattern corresponded with the effects of $\mathrm{pH}$ upon intracellular preparations (Fig. 2). The proteolytic activity as 
measured at these three $\mathrm{pH}$ values was parallel at all stages of the batch growth cycle indicating that the enzymes were not produced in any discernible sequence (O'Sullivan, I970).

The inducibility of the extracellular proteolytic system was demonstrated by transferring mycelium grown on a casein hydrolysate medium to a medium containing casein. Following transfer, after a lag period of about $5 \mathrm{~h}$., proteases appeared in the culture filtrate (Fig. 3).

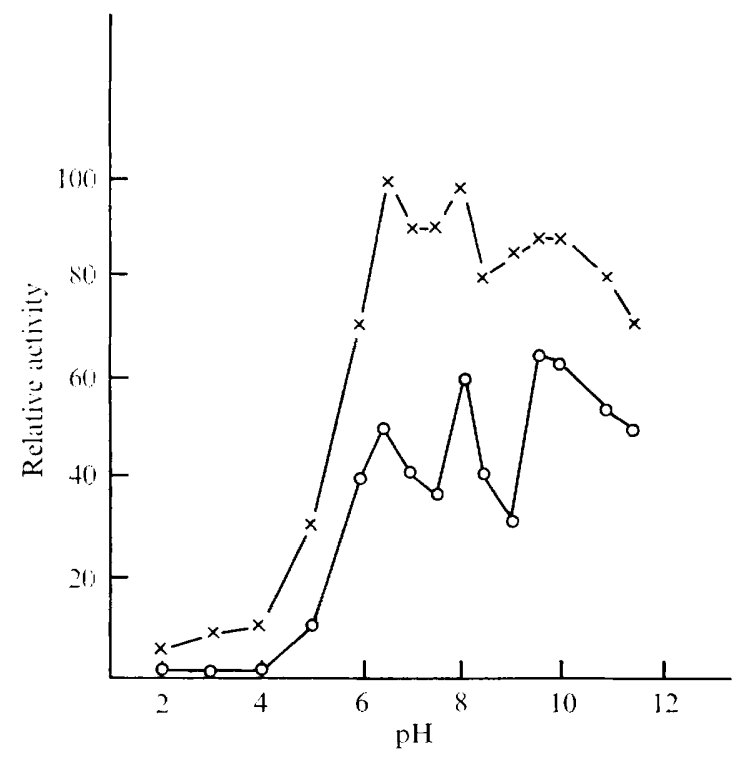

Fig. 2. The effect of $\mathrm{pH}$ on intracellular and extracellular protease preparations. Extracellular preparations were crude dialysed organism-free culture filtrates taken from exponentially growing cultures $(x-x)$. The intracellular preparation was an extract of the mycelium prepared by sandgrinding $(\mathrm{O}-\mathrm{O})$. The buffering system was $0 \cdot 1 \mathrm{M}$-borate-phosphoric acid.

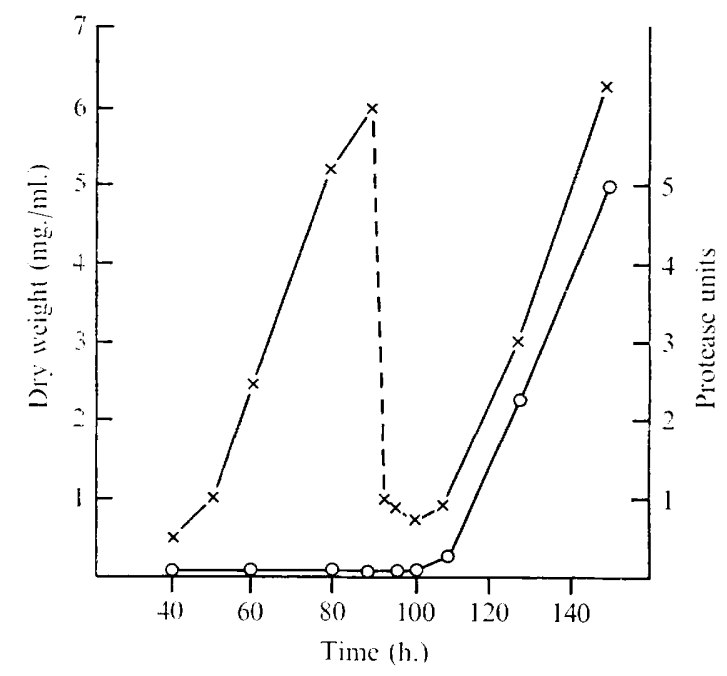

Fig. 3. Induction of proteases. The fungus was grown on casein hydrolysate $(\times--\times)$, harvested, washed and transferred to casein medium. No extracellular protease activity was detectable during growth on casein hydrolysate but after a $5 \mathrm{~h}$. lag in the casein medium protease appeared in the culture filtrate $(\mathrm{O}-\mathrm{C})$. 
The appearance of the extracellular proteases was accompanied by a sevenfold increase in the intracellular level of protease activity.

The proteases secreted appeared to be endopeptidases since they failed to hydrolyse a number of synthetic peptides; moreover free amino acids were not detectable by paper chromatography of culture filtrates from the exponential phase of growth of the mycelium

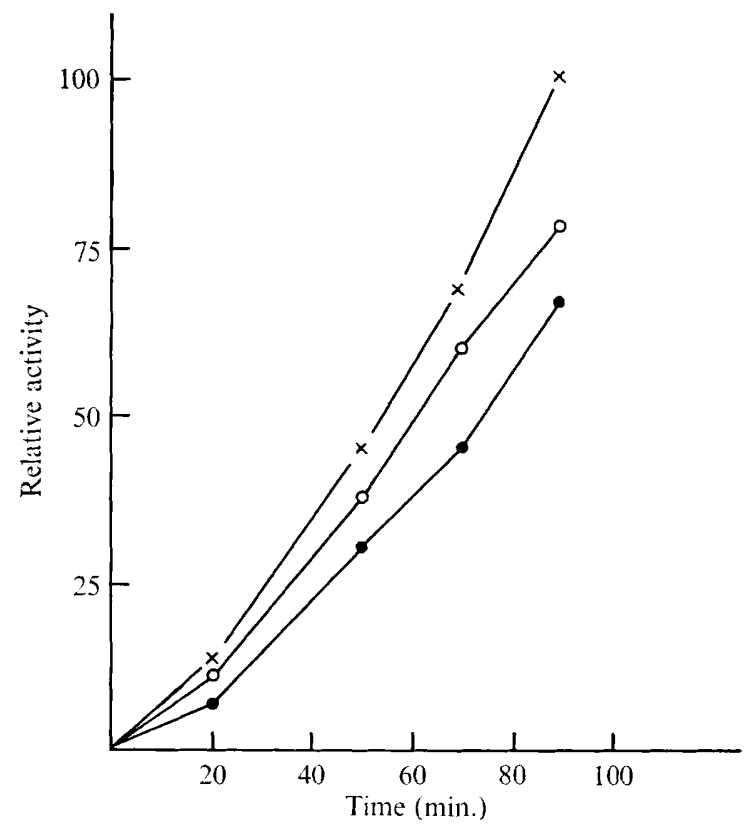

Fig. 4. Potentiation of intracellular protease. An intracellular protease preparation (-) was treated with Triton X-100 at a final concentration of $0.1 \%(v / v)(x-x)$ during the assay and by repeated freezing and thawing $\left(\mathrm{O}_{-} \mathrm{O}\right)$. The preparations were assayed over a time course. The results are expressed relative to the Triton-treated sample.

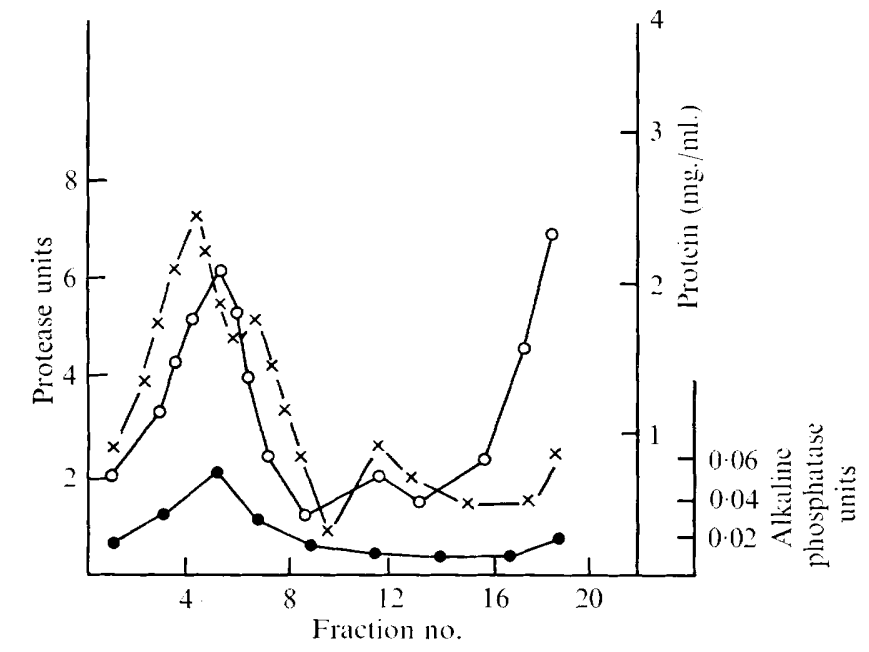

Fig. 5. Sucrose density gradient centrifugation. The distribution of protease $(x-x)$, protein $(\mathrm{O}-\mathrm{O})$ and alkaline phosphatase (-) in a mycelial homogenate. 
on casein. This endopeptidase activity is consistent with the observation that the protease system is repressible by amino acids in the medium and the general observation that endopeptidases are the type of protease most commonly produced by micro-organisms.

Localization of proteases. In order to assess the form of intracellular proteases, crude cell extracts were treated with Triton X-IOO or repeated freezing and thawing and compared with an untreated control. Fig. 4 shows increased activity over the control for both of these treatments with the implication that the intracellular protease was membrane bound in some way. An attempt was made to characterize further these membrane/protease complexes by sucrose density-gradient centrifugation. The protease, alkaline phosphatase and protein profiles of such a gradient are shown in Fig. 5. Three peaks of proteolytic activity were found. The relative amounts of ' $\mathrm{pH} 6.6$ ', ' $\mathrm{pH} 8 \cdot 0$ ' and ' $\mathrm{pH} 9.5$ ' enzymes in each of the peaks were found to be similar, indicating that if the particles were of distinct types particular enzymes were not confined to a single particle type.

There were indications from Fig. 5 that alkaline phosphatase activity was structurally separated from protease activity.

\section{DISCUSSION}

Microsporum canis has been shown to produce a complex of extracellular proteolytic enzymes with characteristics which are consistent with their presumed ecological role. The production of extracellular proteases was inducible by protein and repressible by amino acids. This is clearly an advantage to the fungus in vivo and the endopeptidase activity of the enzyme complex is compatible with such a regulatory system. The data on induction suggest that the intracellular level of the enzymes is raised and that they are liberated by a true secretory process. The evidence for the latter rests upon the significance of alkaline phosphatase as a marker of cell lysis and the localization studies.

It is often difficult to differentiate between products of autolysis and secretion. This is due in part to the dearth of information on the subcellular localization of enzymes in fungi and the consequent lack of reliable intracellular markers. Alkaline phosphatase was chosen in this study since it is localized in a cell compartment and is easily assayed. Dermatophytes tend to be favoured by alkaline ecosystems and alkaline phosphatase is therefore preferable to acid phosphatases which have been exploited for this purpose in other systems. The criteria used to assess the extracellularity of an enzyme have been discussed by Pollock (1962). On these criteria the Microsporum canis proteases induced by protein are truly extracellular. Characteristics of extracellular proteases from other systems (e.g. Hofman \& Shaw, I964; Burgum \& Prescott, 1965) suggest that a low sulphur content and endopeptidase activity are general features of such systems. In the latter respect the $M$. canis system conforms to the pattern.

The apparent separation of the peaks of activity of alkaline phosphatase and protease may indicate that they are located in structurally distinct particles. This separation, though not great, has been consistently observed in five experiments. Because the homogenization procedure used would cause damage to some of the organelles it cannot be said that the three peaks of activity noted (Fig. 5) represent distinctly different particles. It is also possible that proteases solubilized during the extraction procedures may have become adsorbed onto particulate debris.

The separation of alkaline phosphatase from proteinase activity temporally and possibly structurally is interesting in that a conventional lysosomal structure is unlikely to be present. Acid phosphatases in mammalian tissues are located in lysosomes together with proteases and other hydrolytic enzymes. The alkaline phosphatase of Microsporum canis may be 
immured in a structure functionally analogous to a mammalian lysosome as its release into the culture medium coincides with autolysis of the mycelium. This structural separation justifies the use of alkaline phosphatase as an autolytic marker and points to the possibility of proteases being secreted independently of certain other hydrolytic enzymes.

Matile $(1965 ; 1967)$ has studied the subcellular localization of proteolytic enzymes in Neurospora crassa and shown them to be stored in vesicles which he called protease particles. Similar vesicles were isolated from yeast (Matile \& Wiemken, 1967) and from Coprinus (Iten \& Matile, 1970). Matile showed that in N. crassa the protease particles were the vehicle of secretion. It seems likely that a similar mechanism operates in Microsporum canis since unpublished electron-microscope studies of sections of hyphal tips from casein-induced cultures show the development of vesicular bodies not present in the non-induced hyphae.

We thank Mrs P. Mogensen and her staff in this Department for technical assistance, Mr G. Pepin of the Central Veterinary Laboratories for the supply of a fresh isolate of Microsporum canis, and the Medical Research Council for supporting this work.

\section{REFERENCES}

Anson, M. L. (1938). The estimation of pepsin, trypsin, papain and cathepsin with haemoglobin. Journal of General Physiology 22, 79-89.

BAXTER, M. \& MANN, P. R. (I969). Electron microscope studies of the invasion of human hair in vitro by three keratinophilic fungi. Sabouraudia $7,33-37$.

Burgum, A. A. \& Prescott, J. M. (I965). Isolation and characterization of a fungal endopeptidase. Archives of Biochemistry and Biophysics 3, 39I-398.

Chattaway, F. W., Ellis, D. A. \& Barlow, A. J. E. (1963). Peptidases of dermatophytes. Journal of Investigative Dermatology 4I, 3I-37.

Chesters, C. G. C. \& MAthison, G. E. (1963). The decomposition of wool keratin by Keratinomyces ajelloi. Sabouraudia 2, 225-237.

Cruikshank, C. N. D. \& Trotter, M. D. (1956). Separation of epidermis and dermis by filtrates of Trichophyton mentagrophytes. Nature, London $\mathbf{1 7 7}, 1085$.

Day, W. C., Toncic, P., Stratman, S. L., Leeman, U. \& Harmon, S. R. (1968). Isolation and properties of an extracellular protease of Trichophyton granulosum. Biochimica et biophysica acta 167, 697-606.

ENGLish, M. P. (1963). The saprophytic growth of keratinophilic fungi on keratin. Sabouraudia 2, i1 5-130.

ENGLish, M. P. (1968). The developmental morphology of the perforating organs and eroding mycelium of dermatophytes. Sabouraudia 6, 21 8-227.

Grassman, W. \& HeYde, W. (I929). Alkalimetrische Mikrobestimmung der Aminosäuren und Peptide. Hoppe-Seyler's Zeitschrift für physiologische Chemie $\mathbf{1 8 3}, 32$.

Hofman, T. \& Shaw, R. (1964). Proteolytic enzymes of Penicillium janthinellum. I. Purification and properties of a trypsinogen-activating enzyme (peptidase A). Biochimica et biophysica acta 92, 543-557.

ITEN, W. \& MATILE, P. (1970). Role of chitinase and other lysosomal enzymes of Coprinus lagopus in the autolysis of fruiting bodies. Journal of General Microbiology 61, 30I-309.

KEDDIE, F. M. (1967). Further investigations of the electron microscopic examination of human hair naturally infected by Microsporum gypseum. Sabouraudia 6, I-4.

Kunitz, M. (1947). Crystalline soybean trypsin inhibitor. Journal of General Physiology 30, 29 I-3 10.

Lowry, O. H., Rosebrough, N. J., FarR, A. L. \& Randall, R. J. (I95I). Protein measurement with the Folin phenol reagent. Journal of Biological Chemistry 193, 265-275.

Mathison, G. E. (1964). The microbiological decomposition of keratin. Annales de la Société belge de médecine tropicale $44,767-792$.

Matheson, A. T. \& Tattrie, B. L. (I964). A modified Yemm and Cocking reagent for peptidase assay. Canadian Journal of Biochemistry 42, 95-99.

MATILE, P. (1965). Intracellular localization of proteolytic enzymes of Neurospora crassa. I. Function and subcellular distribution of proteolytic enzymes. Zeitschrift für Zellforschung und mikroskopische Anatomie 65, 884-893. 
MATILE, P. (1967). Porosity of the cell wall as related to the secretion of proteolytic enzymes in Neurospora crassa. Neurospora Newsletter 12, 6.

Matile, P. \& WiemKen, P. (I967). The vacuole as the lysosome of the yeast cell. Archiv für Mikrobiologie 56, I48-I55.

MERCER, E. H. \& VeRMA, B. S. (I963). Hair digested by Trichophyton mentagrophytes. An electron microscope examination. Archives of Dermatology. 87, 357-360.

O'Sullivan, J. (1970). The proteolytic system of Microsporum canis. Ph.D. Thesis, University of London.

O'Sullivan, J. \& Mathison, G. E. (I970). Interference by monosaccharides with the estimation of tyrosine and proteins using the Folin-Ciocalteu phenol reagent. Analytical Biochemistry 35, 540-542.

Pollock, M. R. (1962). Exoenzymes. In The Bacteria, vol. iv. Edited by I. C. Gunsalus and R. Y. Stanier. New York: Academic Press.

RoBerts, F. F. \& DoETsCH, R. N. (1967). Purification of a highly active protease from a Microsporum species. Antonie van Leeuwenhoek 33, 145.

Schwert, G. W., Neurath, H., Kaufman, S. \& Snoke, J. E. (1948). The specific esterase activity of trypsin. Journal of Biological Chemistry 172, $22 \mathrm{I}$.

Sмгтн, E. L. (1955). Aminopeptidase (Tripeptidase). In Methods in Enzymology, vol. 2, pp. 83-87. Edited by S. P. Colowick and N. O. Kaplan. New York: Academic Press.

Weary, P. E., Canby, C. M. \& CraWley, E. P. (1965). Keratinolytic activity of Microsporum canis and Microsporum gypseum. Journal of Investigative Dermatology 44, 300-3 I 2.

YU, R. J., HaRmon, S. R. \& Blank, F. (1969). Hair digestion by a keratinase of Trichophyton mentagrophytes. Journal of Investigative Dermatology 53, I66-173. 